\title{
CADMIUM TELLURIDE SOLAR CELLS ON ULTRA-THIN GLASS FOR SPACE APPLICATIONS
}

\author{
S. J. C. Irvine*, D. A. Lamb, A. J. Clayton, G. Kartopu and V. Barrioz \\ CSER, Glyndŵr University, OpTIC, St Asaph Business Park, LL17 OUN, Wales, UK \\ * email: s.irvine@glyndwr.ac.uk
}

\section{Abstract}

This paper details the preliminary findings of a study to achieve a durable thin film CdTe photovoltaic device structure onto ultra-thin space qualified cover glass. An aluminium doped zinc oxide (AZO) transparent conducting oxide (TCO) was deposited directly onto cover glass using metal organic chemical vapour deposition (MOCVD). The AZO demonstrated a low sheet resistance of $10 \Omega / \square$ and high optical transparency of $85 \%$ as well as an excellent adherence and environmental stability. Preliminary deposition of the photovoltaic layers onto the AZO on cover glass, by MOCVD, showed the possibility of such a structure yielding a device conversion efficiency of $7.2 \%$. High series resistance $\left(10 \Omega . \mathrm{cm}^{2}\right)$ and low $\mathrm{V}_{\mathrm{oc}}(586 \mathrm{mV})$ were identified as the limiting factors when compared to the authors platform process on indium tin oxide (ITO) coated aluminosilicate. The coverage of the $\mathrm{Cd}_{1-x} \mathrm{Zn}_{\mathrm{x}} \mathrm{S}$ window layer along with the front contacting of the device was shown to be the major cause of the low efficiency. Further deposition of the AZO/CdTe employing an oxygen plasma cleaning step to the cover glass and evaporated gold front contacts significantly improved the device performance. A best conversion efficiency of $10.2 \%$ with series resistance improved to $4.4 \Omega . \mathrm{cm}^{2}$ and open circuit voltage $\left(\mathrm{V}_{\mathrm{oc}}\right)$ up to $667 \mathrm{mV}$ and good adhesion has demonstrated for the first time direct deposition of CdTe solar cells onto $100 \mu \mathrm{m}$ thick space qualified cover glass.

Keywords: Photovoltaic; flexible solar cells; cadmium telluride; Space applications

\section{Introduction}


Solar power for satellites requires high conversion efficiency and has enabled the very high performance dual and triple junction III-V cells [1] to capture this market. However, there are applications where high power to weight ratio and lower cost are becoming increasingly important and these will require a different approach. Large area and low weight photovoltaic (PV) solar cells will also be needed for space-based solar power (SBSP) [2] and solar electric propulsion (SEP). For these new applications the absolute efficiency is not as much an issue as the specific power to weight ratio and the cost per Watt peak $\left(\mathrm{W}_{\mathrm{p}}\right)$. The approach taken in this research is to use a relatively low cost thin film PV material to deposit PV structures directly onto Space qualified ultra-thin (50-100 $\mu \mathrm{m})$ cover glass manufactured by Qioptiq Space Technology, (QST) (St Asaph, North Wales). The cover glass is designed for protecting more conventional solar cells in space such as crystalline silicon and multi-junction III-V cells. It is a cerium doped micro-sheet glass which avoids colour centres developing under bombardment from radiation in space and the thermal expansion coefficient is matched to the type of solar cell in order to avoid excessive strain while undergoing temperature cycling [3]. Initial deposition onto two types and thicknesses of this cerium-doped micro-sheet is reported in this paper: 50 micron CMG and 100 micron CMX (CMG and CMX are the manufactures', QST, trade names).

The concept of flexible solar cells for space applications is not new, for example, Zwanenburg and Kroon [4] deposited thin film copper indium gallium diselenide (CIGS) onto titanium foil. These authors considered that an efficiency of $12 \%$ AMO was sufficient to achieve the target power output of $100 \mathrm{~W} / \mathrm{m}^{2}$ in a geostationary orbit and a target power to weight ratio of $100 \mathrm{~W} / \mathrm{kg}$. A later paper by Zwanenburg [5] highlighted the problem of delamination under temperature cycling. This paper takes a different approach by using the cover glass as a substrate to minimise thermal stress. In other respects the work of Zwanenburg demonstrated the feasibility of lightweight and flexible thin film PV for space as a viable approach. Deposition of CdTe solar cells onto Corning Willow ${ }^{\mathrm{TM}}$ (Corning Inc., New York) $100 \mu \mathrm{m}$ glass for flexible 
solar cells has been demonstrated by W.L Rance et al. [6] for terrestrial applications where the films showed good adhesion and maximum efficiency of $14.0 \%$.

The purpose of this paper is to demonstrate that CdTe thin film solar cells can be deposited onto space qualified cover glass (50-100 $\mu$ m thick) as an alternative route for light weight and low cost flexible PV for space deployment. The potential for thin film PV on CMG cover glass is illustrated in Table 1 which makes a comparison with triple junction III-V cells and crystalline silicon. This illustrates that, even with just $12 \%$ module efficiency, it will be possible to achieve a higher specific power using the thin film CdTe approach than for single junction silicon and triple junction III-V. It also compares favourably with Ref. 4 which also predicted a specific weight for their copper indium gallium diselenide (CIGS) flexible structure of $0.24 \mathrm{~kg} / \mathrm{m}^{2}$. Any improvement in device efficiency over the target $12 \%$ would reduce the predicted specific power of $0.67 \mathrm{~kg} / \mathrm{kW}$. This would enable more PV power per payload on launch.

The chosen method for deposition of the solar cell structures was metal-organic chemical vapour deposition (MOCVD), the advantages of this method for deposition onto cover glass is described in the following section.

\section{MOCVD of CdTe solar cells}

CdTe PV modules are now manufactured on a large scale for terrestrial solar power with record module efficiency of $16.1 \%$ (First Solar Inc., Tempe, Arizona) [7] and record cell efficiency of 19.6\% (General Electric, Fairfield, Connecticut, USA) [8]. The deposition methods are based on vacuum evaporation and are well suited to high volume and low cost manufacture. The application of MOCVD is appropriate where more complex compositions and structures are needed. This versatility is appropriate to the application of solar cells for space where materials design has to consider durability in the space environment as well as a good beginning of life performance. Particular features of MOCVD are adjustable bandgap window layer, thickness control, doping control and atmospheric pressure deposition. Details of the MOCVD process, 
including the choice of precursors and deposition temperatures have been given elsewhere [9]. One feature is that it has been possible to directly grow the alloy $\mathrm{Cd}_{1-x} \mathrm{Zn}_{x} S$ to replace the CdS window layer that absorbs below $500 \mathrm{~nm}$. With MOCVD it has been shown that a composition of $x=0.7$ is necessary to push the short wavelength cut-off from $500 \mathrm{~nm}$ down to $400 \mathrm{~nm}$ [10]. Furthermore it has been possible to demonstrate control of the absorber layer thickness to achieve ultra-thin CdTe absorber layers less than $1 \mu \mathrm{m}$ thick [11]. Optimising the thickness of the CdTe absorber layer will be necessary to both maximise on the absorption of solar radiation and to minimise thin film strain.

An in-line MOCVD approach has been considered to make the MOCVD process compatible with large volume production and can achieve a large increase in deposition rate and organometallic precursor utilisation [12]. A further development using a unique chamberless inline MOCVD system will enable scale-up from the current $15 \mathrm{~cm}$ wide injectors to greater than 1 metre in width and the potential for materials utilisation of over $50 \%$.

\section{Nucleation and growth of AZO onto cover glass}

Deposition of the CdTe solar cell structure requires a highly adherent layer of a transparent conducting oxide (TCO) onto the cover glass, which in this case is aluminium-doped zinc oxide (AZO). This not only provides the front contact for the solar cell but also acts as the template for growth of subsequent layers in the structure. For efficient solar cells the AZO must have high transparency from the ultra-violet (UV) through to the near infrared where the CdTe absorber cuts-off around $900 \mathrm{~nm}$. Longer wavelengths are not usefully absorbed in this structure. The precursors used in these experiments were Diethyzinc (DEZn), Tertiary-butanol (TBA) and Trimethylaluminium (TMA) at a substrate temperature of $400^{\circ} \mathrm{C}$. The TBA to DEZn ratio was maintained at 3:1 thus providing an excess of oxygen and avoiding zinc rich films in which optical transparency would be greatly reduced [13]. Previous authors have shown that, depending upon deposition temperature and technique there is a wide window of aluminium 
incorporation (1 to 10 atomic \%) which will yield highly conducting films $[14,15]$. The AZO developed for this research employed a DEZn to TMA ratio of 1 to 0.1 at the $400{ }^{\circ} \mathrm{C}$ deposition temperature. For a $700 \mathrm{~nm}$ film this ratio gave excellent electrical properties $(10 \Omega / \square)$ whilst maintaining high optical transparency (85 \% average transmittance $380-780 \mathrm{~nm}$ referenced to air). The aluminium incorporation within the films was confirmed by Energy Dispersive X-ray to be 3.3 atomic $\%$.

The films were subjected to the Scotch Tape test (MIL-C-675C 3.8.5) and 24 hour exposure to $70^{\circ} \mathrm{C}$ and $75 \%$ relative humidity demonstrating excellent adherence and optical and electrical environmental stability respectively.

The sheet resistance and transparency were adjusted by changing the film thickness using the same deposition conditions as above. As can be seen from Fig. 1, the sheet resistance has a linear relationship with film thickness, going from $9.7 \Omega / \square$ at $550 \mathrm{~nm}$ to $3.1 \Omega / \square$ at $2100 \mathrm{~nm}$ thickness. The transmission spectra for different AZO thicknesses were measured using the integrating sphere accessory of a Varian Cary 5000 UV-Vis spectrometer (Varian Inc., Palo Alto, California) and are shown in Fig. 2. For the thicker film the plasma edge will significantly limit the transmission at the absorption edge of the CdTe absorber and in the visible region the transmission is limited to $75 \%$ maximum which is a $15 \%$ loss compared with the uncoated cover glass transmission. However, for the thinner AZO films the maximum transmission was $85 \%$ representing only $5 \%$ absorption and a plasma edge beyond $1000 \mathrm{~nm}$. For the purposes of making thin film PV devices onto cover glass the thinner AZO films were deposited with thickness of $700 \mathrm{~nm}$ with an optical transparency of $85 \%$ and sheet resistance of $10 \Omega / \square$.

\section{CdTe PV devices on cover glass}

A well adhered AZO/CdTe PV structure on CMG cover glass is demonstrated in figure 3 . The CdTe:As/Cd $\mathrm{Cd}_{1-x} \mathrm{Zn}_{\mathrm{x}} \mathrm{S}$ structure was grown onto an untreated CMG cover glass substrate with an 
AZO TCO as previously described. The test devices were defined with $0.25 \mathrm{~cm}^{2}$ gold contacts which were $160 \mathrm{~nm}$ thick. Some patchiness was observed with the $\mathrm{Cd}_{1-x} \mathrm{Zn}_{x} S$ films. This process was carried out in a research MOCVD reactor using $5 \times 5 \mathrm{~cm}^{2}$ substrate area and completed with an in situ $\mathrm{CdCl}_{2}$ activation anneal [9]. A strip $4 \mathrm{~mm}$ wide was masked on one side after the AZO deposition and before subsequent device deposition to enable formation of a front contact with silver paint. For our standard devices on $1.1 \mathrm{~mm}$ thick indium tin oxide (ITO) coated aluminosilicate glass the TCO layer was revealed by abrading the relatively soft CdTe:As/Cd${ }_{1}$. ${ }_{x} \mathrm{Zn}_{\mathrm{x}} \mathrm{S}$ layers. This was not possible with the $50 \mu \mathrm{m}$ thick $\mathrm{CMG}$ cover glass as the pressure needed for abrasion risked cracking the substrate. However, the aforementioned masking with thin graphite strips during device growth was successful and did not perturb the growth in the surrounding area. The completed device structure with evaporated gold contacts is shown in Fig. 3 which also serves to illustrate the flexibility of this very thin structure. Table 2 shows a comparison of the best device from this array with an equivalent device structure grown onto ITO coated $1.1 \mathrm{~mm}$ thick ITO coated aluminosilicate glass (ASG) substrate. The $4 \times 7$ array of devices on the standard substrate had a small variance as indicated with the best and mean device performance parameters. The same was not true of this first attempt at CdTe devices on the CMG cover glass where only 5 contacts responded out of 16 . The best efficiency for this preliminary device was $7.2 \%$ compared with the best and mean efficiency of $14.4 \%$ and $13.4 \pm$ $0.5 \%$,respectively, on the ASG substrate. Closer examination of device parameters from the JV curves under AM1.5 illumination shows that the lower efficiency arises from a low open circuit voltage $\left(\mathrm{V}_{\mathrm{oc}}\right)$ of $586 \mathrm{mV}$ compared with $788 \mathrm{mV}$ and a fill factor $(\mathrm{FF})$ of $51 \%$ compared with $76 \%$. The large variance of device performance on the CMG cover glass is indicative of substrate contamination which may have caused patchiness in the window layer thickness. This has been shown previously by Brooks et al [16] using multi-wavelength laser beam induced current (LBIC) mapping], and as a consequence reduces the $\mathrm{V}_{\mathrm{oc}}$. 
The cause of the low FF is attributable to the high series resistance, $10 \Omega . \mathrm{cm}^{2}$ compared with $2.2 \Omega . \mathrm{cm}^{2}$ for the best device on ASG. Only having a front contact on one side of the device will cause a larger resistance contribution from the AZO although a previous study on the effect of TCO resistance and device configuration would indicate that this would only contribute in the region of $3 \Omega . \mathrm{cm}^{2}$ to the series resistance with the AZO sheet resistance of $10 \Omega / \square[17]$. The silver paint applied to the AZO front contact was also suspected of introducing a high contact resistance thus contributing to the unusually high series resistance. These issues were resolved when moving to the 100 micron CMX by an improved surface preparation of the CMX substrate and to replace the silver paint with evaporated gold for the front contact. The CMX cover glass was exposed to oxygen plasma prior to loading into the MOCVD reactor for AZO deposition. The oxygen plasma was generated in a $40 \mathrm{kHz} / 200 \mathrm{~W}$ plasma chamber exposing the substrate for 6 minutes at $90 \%$ power and $60 \mathrm{sccm}$ of high purity oxygen. Plasma cleaning has recently demonstrated the capability of depositing more uniform CdS window layers (compared to standard wet cleaning methods) with greatly reduced pin-hole defects, improving the $\mathrm{V}_{\mathrm{oc}}$ of CdS/CdTe solar cells $[18,19]$. The $\mathrm{V}_{\text {oc }}$ improvement is due to prevention of low photovoltage CdTe/TCO interfaces forming locally. Table 3 shows the device results from the row adjacent to the edge front contact and a second front contact on the other side of the devices. Both front contacts were evaporated gold as were the back contact pads. The series resistance has reduced to the region of $4 \Omega . \mathrm{cm}^{2}$; much closer to the comparative devices on ASG. From these four devices it can be seen that there is considerable variation in the shunt resistance which indicates that although surface preparation has improved considerably over the baseline there is the need for further development of this process. The $\mathrm{V}_{\mathrm{oc}}$ is also much improved but falls short of that expected on ASG substrates. It is suggested that this is also related to the pin-holes in the AZO causing local regions of poor CdTe:As $/ \mathrm{Cd}_{1-\mathrm{x}} \mathrm{Zn}_{\mathrm{x}} \mathrm{S}$ nucleation. The best device in this array, from column 2, has a respectable AM 1.5 efficiency of $10.2 \%$ and shows promise that uniform efficiency of the target $12 \%$ is attainable. 
A comparison of the J-V curves under AM 1.5 illumination is shown in Fig 4 for the best devices from the first (on CMG cover glass) and second (on CMX cover glass) device structure synthesis. It can be seen that the second (improved) process gives much steeper forward bias characteristics, consistent with the lower series resistance and higher $\mathrm{V}_{\text {oc }}$ can be seen. There is some decrease in the $\mathrm{J}_{\mathrm{sc}}$ for the second (improved) process but variations between devices and the non-optimum surface preparation of the cover glass substrates is the most likely cause to account for the decrease of just $2 \mathrm{~mA} \mathrm{~cm}^{-2}$. Variations in the surface of the prepared cover glass substrate will cause variations in thickness in the window layer which in turn has been shown to create non-uniformity of the photo-current, probably through locally higher recombination rates [16]. This will also influence the $\mathrm{V}_{\text {oc }}$ which, although having improved, is still not comparable with the devices on the ITO/ASG substrates. However, these much improved $V_{\text {oc }}$ and FF values for the plasma cleaned cover glass gives encouragement to improve the process and achieve the higher performance expected.

\section{Conclusions \& Outlook}

Preliminary results have been presented on the deposition of CdTe solar cells using MOCVD onto space qualified CMG and CMX cover glass substrates demonstrating over $10 \%$ AM 1.5 device performance. This is the first report of CdTe thin film solar cells being deposited directly onto the space qualified CMG and CMX cover glass. The adhesion under bend tests looks promising but further extensive tests on the mechanical properties and temperature cycling will have to be carried out to determine the durability of this approach. The thin film solar cells deposited onto cover glass is expected to lead to higher specific power for space applications where large PV arrays are required. Combining this with the innovative chamberless in-line MOCVD process (under development in CSER laboratories) could lead to high volumes of solar power for space deployment.

\section{Acknowledgements}


The authors acknowledge financial support from the Engineering and Physical Science Research Council (EPSRC) Grant Ref. EP/K019597/1

\section{References}

1. H. Cotal, C. Fetzer, J. Boisvert, G. Kinsey, P. Herbert, H. Yoon, N. Karam, Energy Environ. Sci.,2 174 (2009)

2. W. Sebolt, Acta Astronautica 55389 (2004)

3. J. S. Stroud, J. Chem. Phys. 35 (3), 844-850 (1961)

4. R. Zwanenburg and M. Kroon, Proc. 'Seventh European Space Power Conference', Stresa, Italy, 9-13 May 2005 (ESA SP-589, May 2005)

5. R. Zwanenburg, Proc. of the '8th European Space Power Conference', Constance, Germany, 14-19 September 2008 (ESA SP-661, September 2008)

6. W.L. Rance, J.M. Burst, M.O. Reese, D.M. Meysing, C.A. Wolden, T.A. Gessert, S. Garner, X. Li, P. Cimo, C. Kosik-Williams, T.M. Barnes, Proc. 39th IEEE Photovotaics Spec. Conf., Tampa, USA, 2013.

7. http://investor.firstsolar.com/releasedetail.cfm?releaseid=755244 (09/04/2013)

8. M. A. Green, K. Emery, Y. Hishikawa, W. Warta, E. D. Dunlop, Solar Cell Efficiency Tables (v. 42), Prog. Photovolt. Res. Appl. 21, 827 (2013)

9. S. J. C. Irvine, V. Barrioz, D. Lamb, E. W. Jones, R. L. Rowlands-Jones, J. Cryst. Growth, 310, 5198, (2008)

10. G. Kartopu, A. J. Clayton, W. S. M. Brooks, S. D. Hodgson, V. Barrioz, A. Maertens, D. A. Lamb, S. J. C. Irvine, Prog. Photovolt: Res. Appl. DOI: 10.1002/pip 2272 (2012)

11. A. J. Clayton, S. J. C. Irvine, E. W. Jones, G. Kartopu, V. Barrioz, W. S. M. Brooks, Sol. Energy Mater. Sol. Cells 101, 68 (2012) 
12. V. Barrioz, G. Kartopu, S.J.C. Irvine, S. Monir, X. Yang, J. Cryst. Growth 354, 81(2012)

13. D. A. Lamb and S. J. C. Irvine, J. Cryst. Growth, 273, 111 (2004)

14. J. Hu and R. G. Gordon, J. Appl. Phys. 71 (2) 880 (1992)

15. C. H. Ahn, H, Kim, H. K. Cho, Thin Solid Films 519, 747 (2010)

16. W.S.M. Brooks, S.J.C. Irvine, V. Barrioz, A.J. Clayton, Sol. Energy Mater. Sol. Cells, 101, 26 (2012)

17. S.J.C. Irvine, D.A. Lamb, V. Barrioz, A.J. Clayton, W.S.M. Brooks, S. Rugen-Hankey, G. Kartopu, Thin Solid Films 520, 1167-1173 (2011)

18. D.E. Swanson, R.M. Geisthardt, J.T. McGoffin, J.D. Williams, J.R. Sites, IEEE J. Photovol._3, 838-842 (2013).

19. D. E. Swanson, R. M. Lutze,W. S. Sampath, and J. D.Williams, Proc. 38th IEEE Photovoltaics Spec. Conf., Jun. 2012, pp. 859-863.

\section{Tables}

\begin{tabular}{|c|c|c|c|c|c|}
\hline Technology & Efficiency (\%) & $\begin{array}{c}\text { Cell weight } \\
\left(\mathrm{kg} / \mathrm{m}^{2}\right)\end{array}$ & $\begin{array}{c}\text { Cell weight with } \\
\mathrm{CMG}\left(\mathrm{kg} / \mathrm{m}^{2}\right)\end{array}$ & $\begin{array}{c}\text { Power } \\
\left(\mathrm{kW} / \mathrm{m}^{2}\right)\end{array}$ & $\begin{array}{c}\text { Specific Power } \\
(\mathrm{kW} / \mathrm{kg})\end{array}$ \\
\hline Triple junction & 30 & $0.86^{*}$ & 1.06 & 0.41 & 0.38 \\
\hline Silicon & 16.9 & $0.32^{*}$ & 0.52 & 0.23 & 0.44 \\
\hline CdTe & $12^{* *}$ & $0.03^{* *}$ & 0.24 & 0.16 & $\mathbf{0 . 6 7}$ \\
\hline
\end{tabular}

${ }^{*}$ Manufacturers values for cell and substrate. ${ }^{* *}$ Projected efficiency. ${ }^{* *}$ Theoretical value for cell without substrate. (80 microns of CMG $0.204 \mathrm{~kg} / \mathrm{m}^{2}$ ).

Table 1. A comparison of power density and specific power between different types of solar cell technology showing the potential for CdTe to achieve high specific power. 


\begin{tabular}{|l|c|c|c|}
\hline Parameters & $\begin{array}{c}\text { CdTe Device } \\
\text { on AZO/CMG } \\
\text { BEST }\end{array}$ & $\begin{array}{c}\text { CdTe Device } \\
\text { on ITO/glass } \\
\text { BEST }\end{array}$ & $\begin{array}{c}\text { CdTe Device } \\
\text { on ITO/glass } \\
\text { MEAN }\end{array}$ \\
\hline $\boldsymbol{\eta} \%$ & 7.2 & 14.4 & 13.4 \\
\hline $\mathbf{J}_{\mathbf{s c}} \mathbf{m A ~ \mathbf { ~ m } ^ { - 2 }}$ & 24.3 & 24.0 & 23.6 \\
\hline $\mathbf{V}_{\text {oc }} \mathbf{~} \mathbf{V}$ & 586 & 788 & 770 \\
\hline $\mathbf{F F} \%$ & 50.6 & 76 & 74 \\
\hline $\mathbf{R}_{\mathbf{s}} \boldsymbol{\Omega} \mathbf{c m}^{2}$ & 10.0 & 2.2 & 2.7 \\
\hline $\mathbf{R}_{\mathbf{s h}} \mathbf{\Omega} \mathbf{c m}^{2}$ & 1163 & 2342 & 2120 \\
\hline
\end{tabular}

Table 2. Comparison of best device, measured with AM1.5 solar simulator, from preliminary CdTe device array on CMG cover glass with an equivalent device deposited onto $1.1 \mathrm{~mm}$ thick aluminosilicate glass substrate with indium tin oxide (ITO) TCO showing best and mean device results.

\begin{tabular}{|c|c|c|c|c|}
\hline Parameters & Device 1 & Device 2 & Device 3 & Device 4 \\
\hline$n \%$ & 9.7 & 10.2 & 9.6 & 8.5 \\
\hline $\mathrm{J}_{\mathrm{sc}} \mathrm{mA} \mathrm{cm}^{-2}$ & 22.0 & 22.1 & 22.8 & 20.2 \\
\hline $\mathrm{V}_{\mathrm{oc}} \mathrm{mV}$ & 667 & 667 & 667 & 667 \\
\hline FF \% & 66 & 69 & 63 & 65 \\
\hline $\mathrm{R}_{\mathrm{s}} \Omega \mathrm{cm}^{2}$ & 4.4 & 4.3 & 5 & 4.1 \\
\hline$R_{\mathrm{sh}} \Omega \mathrm{cm}^{2}$ & 421 & 2562 & 876 & 564 \\
\hline
\end{tabular}

Table 3. Device results under AM1.5 illumination for the improved CdTe device array on CMX cover glass for the 4 devices, adjacent to the front contact. 
Figures

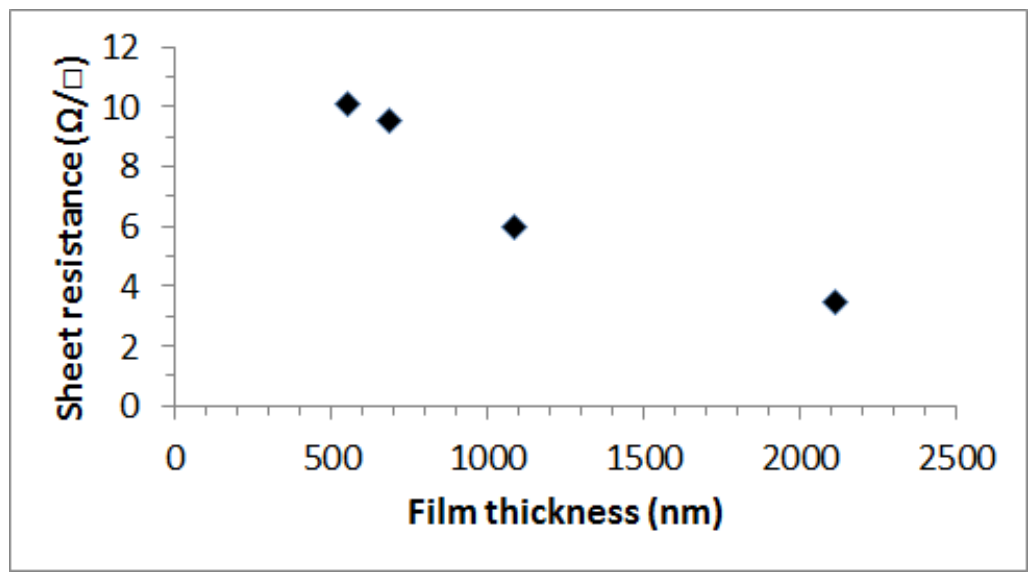

Fig. 1 Measured sheet resistance on $5 \times 5 \mathrm{~cm}^{2}$ films of AZO deposited onto CMG cover glass. 


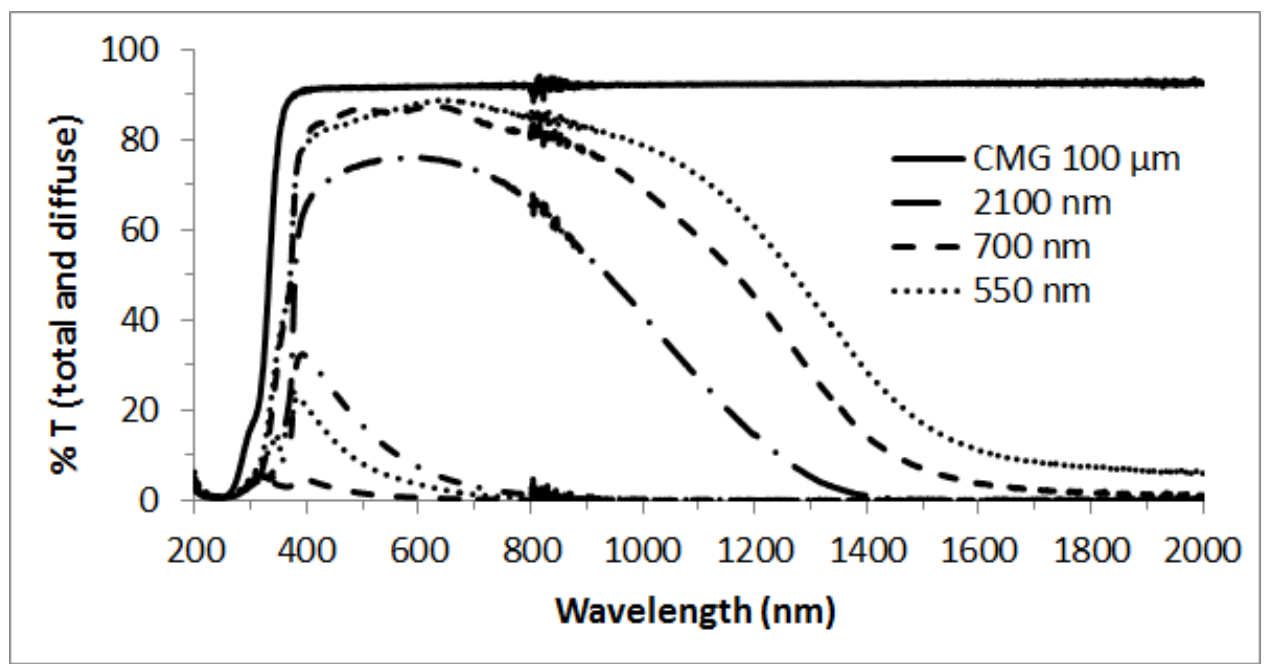

Fig. 2 Transmission spectrum for AZO films with thickness $550 \mathrm{~nm}, 700 \mathrm{~nm}$ and $2100 \mathrm{~nm}$ along with the transmission for the CMG $100 \mu \mathrm{m}$ thick cover glass and the diffuse spectra for each of the AZO films.

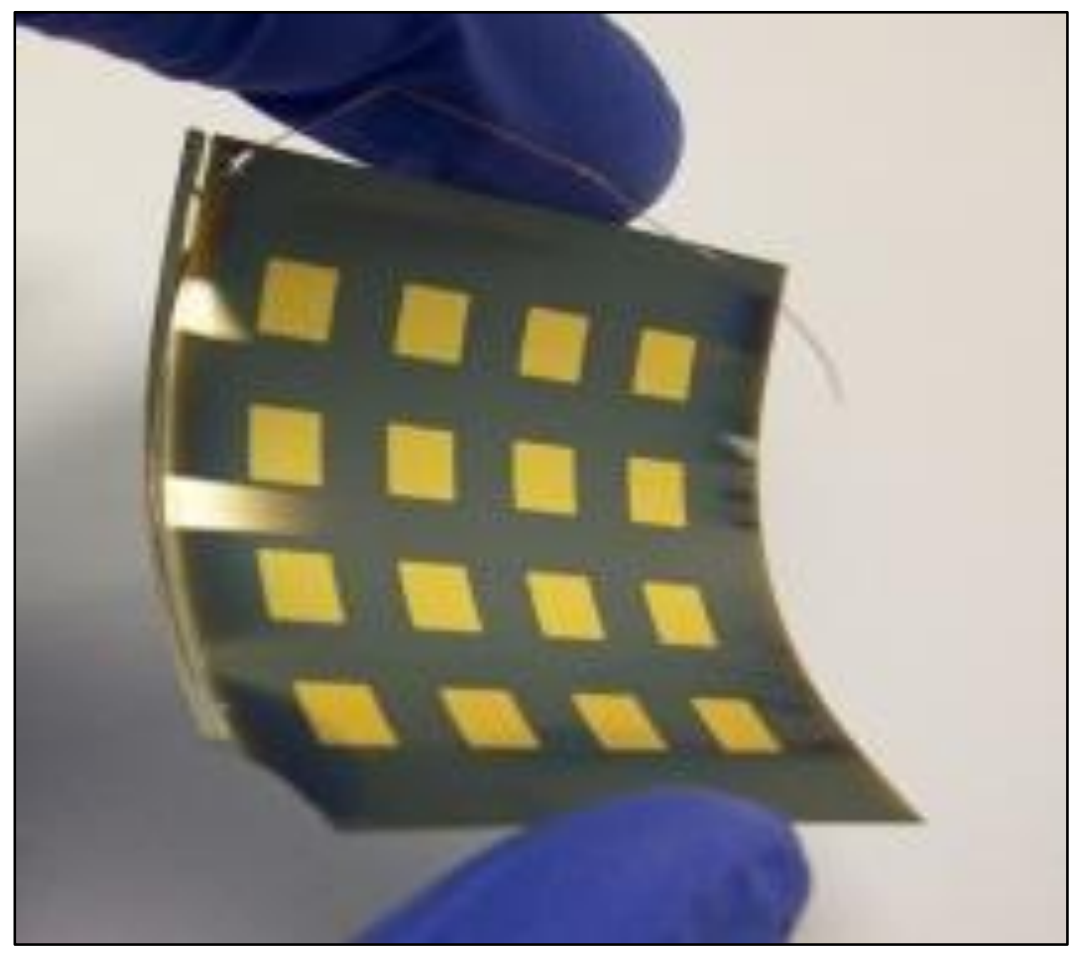

Fig. 3 A complete CdTe solar cell structure onto $50 \mu \mathrm{m}$ CMG cover glass deposited by MOCVD, showing gold back contacts and the silver paste front contact along the left hand edge. 


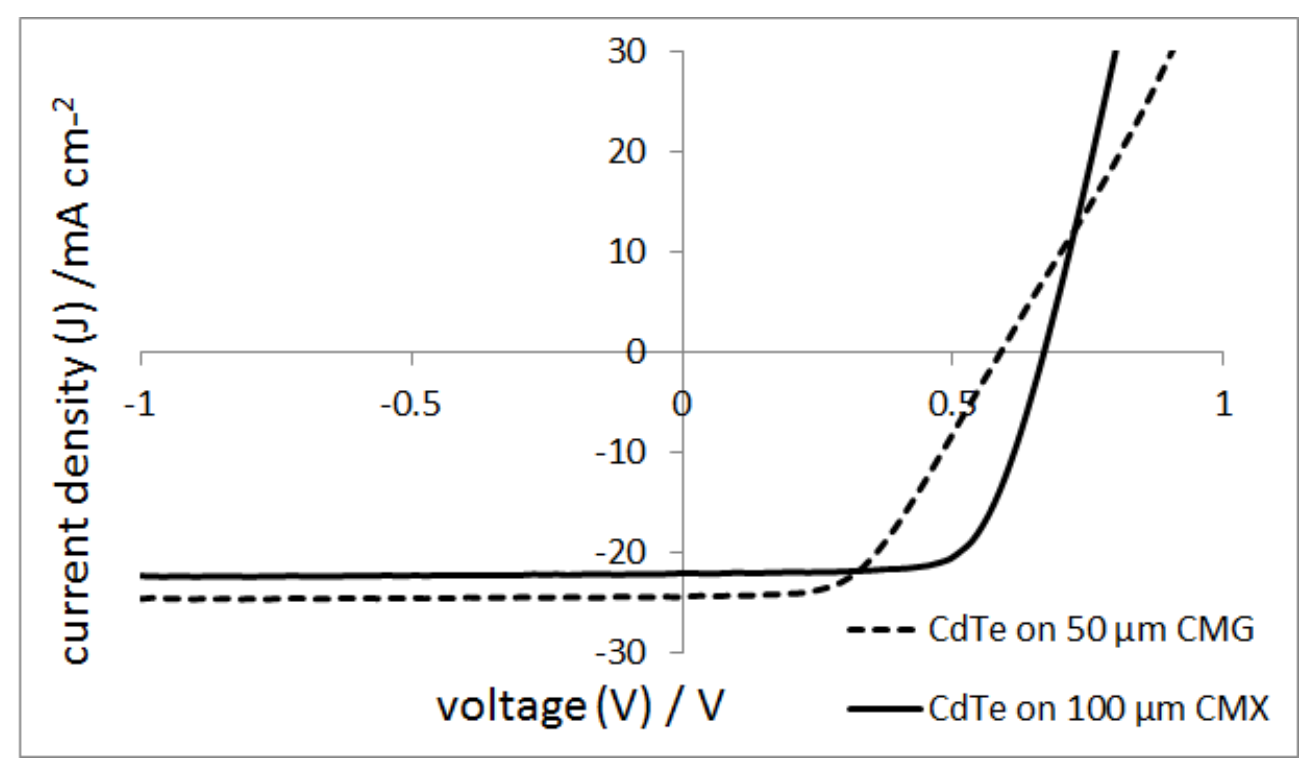

Fig. 4 Current voltage plot of best CdTe photovoltaic device deposited on AZO/50 $\mu \mathrm{m} \mathrm{CMG}$ compared to best device on AZO/100 $\mu \mathrm{m}$ on plasma cleaned CMX. 